\title{
Téoros
}

Revue de recherche en tourisme

\section{Tourisme durable dans les Suds?, Géraldine FROGER, Bruxelles : P.I.E. Peter Lang, 2010, 318 pages, ASSN : 1377-7238}

\section{Alain A. Grenier}

Numéro hors-série, 2012

URI : https://id.erudit.org/iderudit/1037051ar

DOI : https://doi.org/10.7202/1037051ar

Aller au sommaire du numéro

Éditeur(s)

Université du Québec à Montréal

ISSN

0712-8657 (imprimé)

1923-2705 (numérique)

Découvrir la revue

Citer ce compte rendu

Grenier, A. A. (2012). Compte rendu de [Tourisme durable dans les Suds ?,

Géraldine FROGER, Bruxelles : P.I.E. Peter Lang, 2010, 318 pages, ASSN :

1377-7238]. Téoros, 104-104. https://doi.org/10.7202/1037051ar

Ce document est protégé par la loi sur le droit d'auteur. L'utilisation des services d'Érudit (y compris la reproduction) est assujettie à sa politique d'utilisation que vous pouvez consulter en ligne.

https://apropos.erudit.org/fr/usagers/politique-dutilisation/
Cet article est diffusé et préservé par Érudit.

Érudit est un consortium interuniversitaire sans but lucratif composé de l’Université de Montréal, l'Université Laval et l'Université du Québec à Montréal. Il a pour mission la promotion et la valorisation de la recherche. https://www.erudit.org/fr/ 


\title{
POUR EN LIRE PLUS
}

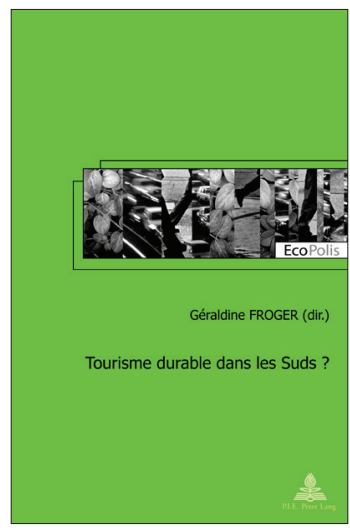

\author{
Tourisme durable dans les Suds? \\ Géraldine FROGER \\ Bruxelles : P.I.E. Peter Lang, 2010, 318 pages \\ ASSN : 1377-7238
}

Ayant comme toile de fond la contradiction des peuples pour leur soif de consommation, d'une part, et leurs inquiétudes face aux impacts de tous les échanges dans un monde multipolaire, l'ouvrage de Géraldine Froger pose un constat sur l'état du développement des pays du «Sud» : les économies de ces pays reposent beaucoup trop sur l'exportation de quelques produits de base (agricoles ou miniers) et sont, de ce fait, tributaires de l'évolution souvent chaotique des cours mondiaux, ne générant que peu de valeur ajoutée compte tenu de la non-transformation locale des produits (Béville, p. 9). Dans le contexte de lutte à la pauvreté par la création d'emploi et de la recherche d'égalité entre les nations pour réduire les risques de conflit, plusieurs pays du Sud choisissent notamment le tourisme comme activité de développement social et économique. À travers leurs ressources naturelles et culturelles, ces pays possèdent des avantages comparatifs importants avec les pays du Nord, d'où viennent la majorité des visiteurs - et principale source de devises étrangères pour plusieurs pays en développement.

Cependant, les modèles de tourismes actuels, souvent implantés à la hâte sans vision à long terme, ne favorisent souvent pas (suffisamment) la destination hôte. Comme le souligne Béville, en préface de l'ouvrage, la question est de savoir si et comment les formes de tourisme différentes du tourisme de masse répondent aux objectifs de développement durable.

Pour répondre à cette question, Géraldine Froger propose ce recueil de 13 articles/chapitres qui proposent, chacun à leur façon, une réflexion critique sur le tourisme durable dans les pays du Suds. L'originalité de l'ouvrage est de ne pas valoriser gratuitement les alternatives, plutôt soumises ici à des analyses critiques qui permettent au lecteur de prendre conscience de la limite des projets d'intentions que demeurent trop souvent plusieurs tourismes alternatifs (on n'a qu'à penser au pseudo «écotourisme» notamment).

L'ouvrage est divisé en trois parties. La première tente un diagnostic et offre une des réflexions sur le tourisme durable dans les Suds, sans s'attacher ni à un continent ni à un pays en particulier. On y questionne l'utopie du tourisme soutenable, des mythes et réalités de l'écotourisme, de l'empreinte écologique du tourisme et de sa mesure, de la contribution du tourisme rural et enfin du financement et de la promotion du tourisme durable.

Les seconde et troisième parties sont respectivement consacrées à des études de cas d'Afrique et d'Amérique latine. Il s'agit de savoir si le développement touristique, les diverses formes alternatives de tourisme et les projets associés dans plusieurs pays de ces deux continents répondent aux objectifs du développement durable. On y traite notamment des enjeux du développement touristique à Madagascar, dans l'ouest de la Tunisie, et du tourisme communautaire comme moteur de développement en Namibie. Pour sa part, la dernière partie de l'ouvrage propose des textes sur les opportunités et limites du tourisme durable en Argentine et au Costa Rica.

Une des forces du livre est la diversité de ses auteurs. Aux sociologues et géographes qui sont souvent sur la ligne de front des études en tourisme, l'équipe qui constitue l'ouvrage de Géraldine Froger compte aussi de nombreux économistes - un domaine souvent moins abordé en tourisme. Froger elle-même n'est pas en reste avec un chapitre d'ouverture très bien développé offrant une occasion de clarification entre les différents concepts utilisés souvent avec confusion par l'industrie. On comprendra pourquoi, à la lecture de l'ouvrage, il y a encore raison de questionner le tourisme durable, d'ici et d'ailleurs, comme celui des Suds. 